lứa tuổi phổ biến nhất phải phẫu thuật điều trị TTTBS. Tuy nhiên chúng tôi cũng nghĩ rằng PTNSMĐR là có thể khả thi với cùng nguyên tắc thực hiện kỹ thuật ở cả lứa tuổi này và đó có thể là hướng nghiên cứu tiếp theo.

\section{KẾT LUẬN}

Nghiên cứu này đã cho thấy kỹ thuật của chúng tôi PTNSMĐR điều trị TTTBS ở trẻ em có thể khả thi, an toàn và có kêt quả thẩm mỹ rât tốt.

\section{TÀI LIÊU THAM KHẢO}

1. Applebaum H, Sydorak R. Duodenal atresia and stenosis-annular pancreas. In: Coran AG, Caldamone A, Adzick NS, Krummel TM, Laberge JM, Shamberger R (2012). Pediatric Surgery. $7^{\text {th }}$ ed. Mosby; pp.1051-1057

2. Bax NM, Ure BM, Van der Zee DC (2001) Laparoscopic duodenoduodenostomy for duodenal atresia. Surg Endosc. 2: 217

3. Chung PH, Wong CW, Ip DK, Tam PK, Wong KK (2017). Is laparoscopic surgery better than open surgery for the repair of congenital duodenal obstruction? A review of the
current evidences. J Pediatr Surg. 52(3): 498-503.

4. Mentessidou A, Saxena AK (2017). Laparoscopic Repair of Duodenal Atresia: Systematic Review and Meta-Analysis. World J Surg. 41(8):2178-2184.

5. Muensterer OJ, Hansen EN (2011). Resection of a duodenal web using single-incision pediatric endosurgery. J Pediatr Surg. 46(5): 989-993.

6. Son TN, Kien HH (2017). Laparoscopic versus open surgery in management of congenital duodenal obstruction in neonates: a single-center experience with 112 cases. J Pediatr Surg. 52(12):1949-1951.

7. Son TN, Liem NT, Kien HH (2015). Laparoscopic simple oblique duodenoduodenostomy in management of congenital duodenal obstruction in children. J Laparoendosc Adv Surg Tech A. 25(2):163-166.

8. van der Zee DC (201)1. Laparoscopic repair of duodenal atresia: Revisited. World J Surg. 35:1781-1784.

\title{
TÌNH TRANG MẤT ỔN ĐINH VI VỆ TINH TRONG UNG THƯ BIỂU MÔ TUYẾN ĐẠI TRỰC TRÀNG GIAI ĐOẠN I-II
}

\section{TÓM TẮT}

Tình trạng mất ổn định của vi vệ tinh đã được xác định là một chỉ số tiên lượng đáng tin cây trong ung thư ĐTT giai đoạn I-II, với một vai trò dự đoán không có lợi ích từ việc hóa trị bổ trợ dựa trên 5-FU. Mục tiêu: Nhân xét môt số mối liên quan giữa tình trang mất ổn định vi vệ tinh, các thể lâm sàng với giai đoạn bệnh và đắc điểm GPB của ung thư ĐTT. Đối tượng và phương pháp nghiên cứu: 53 bệnh nhân ưng thư ĐTT giai đoan I-II đước nghiên cứu HMMD với các dấu ấn MLH1, MSH2, MSH6, PMS2 và các đặc điểm GPB. Kết quả nghiên cứu: $U$ có MSI-H có tỷ lê mắc cao hơn u MSS/MSI-L ở giai đoạn I và thấp hơn ở giai đoạn II (lần lướt là 32,$2 ; 68,8$ so với 24,$3 ; 75,7 \%$ ). Kết luận: MSI-H có tỷ lệ mắc cao hơn u MSS/MSI-L ở giai đoạn I và thấp hơn ở giai đoạn II. Trong đó, thể LS gặp tỷ lệ cao ở giai đoạn II và thẩp nhất ở giai đoạn I.

Tư khóa: Mất ổn định vi vệ tinh, Mô bệnh học, Hóa mô miễn dịch.

\section{SUMMARY}

MSI STATUS OF COLORECTAL ADENOCARCINOMA IN STAGE I-II

\footnotetext{
${ }^{1}$ Bệnh viện K

${ }^{2}$ Trường Đai hoc Y Hà Nôi

Chịu trách nhiệm chính: Nguyễn Văn Chủ

Email: chunv.nch@gmail.com

Ngày nhận bài: 13.11.2020

Ngày phản biện khoa học: 25.12.2020

Ngày duyệt bài: 4.01.2021
}

\section{Nguyễn Văn Chủ ${ }^{1,2}$, Trần Lê Giang ${ }^{2}$}

Background: Microsatellite instability status (MSI) has been identified as a reliable prognostic indicator in stage I-II CRC, with an additional role in predicting the lack of benefit of 5-FU-based adjuvant chemotherapy. Purpose: To review some relationships between MSI status, clinical patterns and stages, pathological characteristics in colorectal cancer. Methods: 53 patients were diagnosed as colorectal adenocarcinoma in stage I-II that are evaluated by pathological features, and IHC stain with MLH1, MSH2, MSH6, PMS2. Results: MSI-H tumors had a higher incidence than MSS / MSI-L tumors in stage I and lower in stage II (32.2; 68.8 vs. $24.3 ; 75.7 \%$ respectively). Conclusion: MSI-H CRCs has a higher incidence than MSS / MSI-L tumors in stage I and lower in stage II. In which, the LS pattern has a high rate in stage II and the lowest in stage I.

Key words: MSI, Histopathology and Immunohistochemistry.

\section{I. ĐĂT VẤN ĐỀ}

Ung thư đại trực tràng (ĐTT) giai đoạn I-II thường biểu hiện tiên lượng tốt. Tỷ lệ sống toàn bộ 5 năm dao động từ 75 đến $87,5 \%$. Tuy nhiên, việc chỉ định hóa trị 5-fluorouracil (5-FU) sau phẫu thuật ở ung thư ĐTT giai đoạn II vẫn còn tranh cãi, vì nó đã được chứng minh rằng tỷ lệ sống tăng thường khổng vượt quá $5 \%$. Nhiều yếu tố tiên lượng đã được đánh giá để xác định phân nhóm ung thư ĐTT giai đoạn II nguy cơ cao, giúp việc chỉ định hóa trị bổ trợ tốt hơn. 
Gần đây, tình trạng mất ổn định của vi vệ tinh (MSI) đã được xác định là một chỉ số tiên lượng đáng tin cậy trong ung thư ĐTT giai đoạn II, với một vai trò dự đoán không có lợi ích từ viêc hóa trị bổ trợ dựa trên 5 -FU. Các bênh nhân mất ổn định vi vệ tinh cao (MSI-H) có tiên lượng và đáp ứng với điều trị khác với các bệnh nhân ổn định vi vệ tinh (MSS). Do vậy việc xác định MSI có ý nghĩa rất quan trọng, không chỉ để sàng lọc hội chứng Lynch mà còn giúp phân biệt giữa ung thư ĐTT khiếm khuyết hệ thống sửa chữa bắt cặp sai với ung thư ĐTT MSS, nó sẽ cung cấp các thông tin có giá trị cho tiên lượng và việc cả thể hóa trong điều trị. MSI có thể gặp trong nhiêu ung thư như ung thư nội mạc tử cung, ung thư da dày, ung thư buồng trứng, ung thư tiền liệt tuyến, ung thư đường gan mật, đường niệu, u não và ung thư da. Trong đó ung thư gặp phổ biến nhất là ung thư ĐTT [1-4]. Ơ Việt Nam, còn ít những nghiên cứu về mất ổn định vi vệ tinh trong ung thư ĐTT. Vì vậy, chúng tôi tiến hành nghiên cứu đề tài này với mục tiêu: "Nhận xét một số mối liên quan giữa tình trạng mât ôn định vi vệ tinh (MSI), thể lâm sàng với đặc điểm GPB của ung thư ĐTT giai đoạn I-II".

\section{II. ĐỐI TƯợNG VÀ PHƯƠNG PHÁP NGHIÊN CỨU}

Đối tượng nghiên cứu: Gồm 53 bệnh nhân ung thư đại trực tràng được điều trị phẫu thuật tại Bênh viện K từ 2017 đến tháng 2018.

\section{Tiêu chuẩn lựa chọn:}

-Bệnh nhân được chẩn đoán ung thư biểu mô ĐTT nguyên phát, giai đoạn I-II.

- Có đầy đủ thông tin lâm sàng: tuổi, giới, nghề nghiệp, triệu chứng, tiền sử,...

-Có đủ mẫu mô để làm hóa mô miễn dịch (HMMD).

Tiêu chuẩn loại trừ: Không đáp ứng được các tiêu chuẩn chọn trên và bệnh nhân được chẩn đoán là u di cắn hoặc tái phát.

Phương pháp nghiên cứu

Thiết kêt nghiên cứu: theo phương pháp nghiên cứu mô tả cắt ngang.

Nghiên cứu về mô bệnh học và HMMD

Kỹ thuật mô học: Đánh giá khối u và hạch theo quy trình giải phẫu bênnh chuẩn.

Kỹ thuật hóa mô miễn dịch: Các mẫu mô được nhuộm HMMD bằng máy với các dấu ấn:
MLH1, MSH2, MSH6 và PMS2.

Quy trình đọc và thẩm định các kết quả: Tác giả đọc tiêu bản nhuộm $H-E, H M M D$, đánh giá kết quả theo tiêu chuẩn quốc tế.

Các biến số được chọn để khảo sát

- Đánh giá kểt quả nhuộm HMMD: MLH1, MSH2, MSH6 và PMS2 để xác định MSI và thể ung thư theo tiêu chuẩn quốc tế.

- Nhận xét mối liên quan giữa MSI, thể lâm sàng với:

+ Giai đoạn u sau phẫu thuật theo AJCC lần thứ 8 [6].

+ Phản ứng đệm lympho dạng Crohn được ghi nhận khi có ít nhất 4 nốt lympho trong một vi trường có độ phóng đại thấp $(\times 4)$ vượt ra khỏi bờ xa của khối $u$ và thường nằm trong lớp hạ thanh mạc hoặc mõ mạc treo

+ Sự xâm nhập lympho u: Các tế bào lympho xâm nhập vào tế bào $u$ khi có ít nhất 5 tế bào lympho ở ít nhất một vi trường có độ phóng đại cao $(\times 40)$ và ít nhất 10 vi trường có độ phóng đại cao

+ Typ mô bênh học: tuyến, tế bào nhẫn hoặc chế nhày, thể tủy theo WHO 2019.

Quản lý thông tin và phân tích dữ liệu: Các trường hợp nghiên cứu được mã hóa dữ liệu. Xử lý số liệu bằng phần mềm SPSS 20.0, sử dụng test $\chi^{2}$.

Đao đức trong nghiên cứu: Đề tài được hội đồng khoa học của Bệnh viện $\mathrm{K}$ phê duyệt.

\section{KẾT QUẢ NGHIÊN CỨU}

Bảng 1. Tình trạng MSI

\begin{tabular}{|c|c|c|}
\hline & $\mathbf{N}$ & $\mathbf{\%}$ \\
\hline MSS/MSI-L & 37 & 69,8 \\
\hline MSI-H & 16 & 30,2 \\
\hline Tống số & 53 & 100,0 \\
\hline
\end{tabular}

Nhân xét: MSI-H chiếm tỷ lê $30,2 \%$, trong khi đó các u MSS/MSI-L có tỷ lệ là 69,8\%.

Bảng 2. Thể lâm sàng ung thư ĐTT

\begin{tabular}{|c|c|c|}
\hline Ung thư ĐT & $\mathbf{N}$ & $\mathbf{\%}$ \\
\hline Đơn lẻ & 37 & 69,8 \\
\hline Đơn lè/hội chứng Lynch & 9 & 16,7 \\
\hline Hội chứng Lynch & 7 & 13,5 \\
\hline Tống số & 53 & 100,0 \\
\hline
\end{tabular}

Nhận xét: Ung thư ĐTT đơn lẻ chiếm phần lớn $(69,8 \%)$, các trường hợp chưa rõ là $16,7 \%$, trong khi đó hội chứng Lynch là 13,5\%.

Bảng 3. Mối liên quan với giai đoạn TNM sau mố

\begin{tabular}{|c|c|c|c|c|c|c|}
\hline & \multicolumn{2}{|c|}{ MSS/MSI-L } & \multicolumn{2}{c|}{ MSI-H } & \multicolumn{2}{c|}{ Tống số } \\
\cline { 2 - 7 } & $\mathbf{N}$ & $\mathbf{\%}$ & $\mathbf{N}$ & $\mathbf{\%}$ & $\mathbf{N}$ & $\mathbf{\%}$ \\
\hline I & 9 & 24,3 & 5 & 32,2 & 14 & 26,4 \\
\hline II & 28 & 75,7 & 11 & 68,8 & 39 & 73,6 \\
\hline Tống số & $\mathbf{3 7}$ & $\mathbf{6 9 , 8}$ & $\mathbf{1 6}$ & $\mathbf{3 0 , 2}$ & \multicolumn{2}{|c|}{$\mathbf{5 3}$} \\
\hline
\end{tabular}


Nhận xét: U có MSI-H có tỷ lệ mắc cao hơn u MSS/MSI-L ở giai đoạn I và thấp hơn ở giai đoạn II (lần lượt là 32,$2 ; 68,8$ so với 24,$3 ; 75,7 \%)(p=0,592)$.

Bảng 4. Mối liến quan giữa thể lâm sàng với giai đoạn TNM sau mổ

\begin{tabular}{|c|c|c|c|c|c|c|c|c|}
\hline & \multicolumn{2}{|c|}{ Đơn lè } & \multicolumn{2}{c|}{ Đơn lẻ/LS } & \multicolumn{2}{c|}{ LS } & \multicolumn{2}{c|}{ Tống số } \\
\cline { 2 - 9 } & $\mathbf{N}$ & $\mathbf{\%}$ & $\mathbf{N}$ & $\mathbf{\%}$ & $\mathbf{N}$ & $\mathbf{\%}$ & $\mathbf{N}$ & $\mathbf{\%}$ \\
\hline I & 9 & 24,3 & 4 & 44,4 & 1 & 14,3 & 14 & 26,4 \\
\hline II & 28 & 75,7 & 5 & 55,6 & 6 & 85,7 & 39 & 73,6 \\
\hline Tống số & 37 & 69,8 & 9 & 16,7 & 7 & 13,5 & \multicolumn{2}{|c|}{71} \\
\hline
\end{tabular}

Nhânn xét: Thế LS gặp tỷ lệ cao ở giai đoạn II $(85,7 \%)$ và thấp nhất ở giai đoạn I là $14,3 \%$. Trong khi đó thể đơn lẻ/LS chiếm tỷ lệ thấp nhất ở giai đoạn II $(55,6 \%)(p=0,346)$.

Bảng 5. Mối liên quan MSI với typ MBH

\begin{tabular}{|c|c|c|c|c|c|c|}
\hline & \multicolumn{2}{|c|}{ MSS/MSI-L } & \multicolumn{2}{c|}{ MSI-H } & \multicolumn{2}{c|}{ Tống số } \\
\cline { 2 - 7 } & $\mathbf{N}$ & $\mathbf{\%}$ & $\mathbf{N}$ & $\mathbf{\%}$ & $\mathbf{N}$ & $\mathbf{\%}$ \\
\hline Tuyến & 27 & 72,9 & 9 & 56,2 & 36 & 67,9 \\
\hline Nhày & 10 & 27,1 & 5 & 31,2 & 15 & 28,3 \\
\hline Tế bào nhân & 0 & 00 & 1 & 6,3 & 1 & 1,9 \\
\hline Tủy & 0 & 00 & 1 & 6,3 & 1 & 1,9 \\
\hline Tống số & $\mathbf{3 7}$ & $\mathbf{6 9 , 8}$ & $\mathbf{1 6}$ & $\mathbf{3 0 , 2}$ & $\mathbf{5 3}$ & $\mathbf{1 0 0 , 0}$ \\
\hline
\end{tabular}

Nhân xét: Typ nhày, tế bào nhần, tủy chiếm tỷ cao hơn ở MSI-H là $31,2 \%$, $6,3 \%$ và $6,3 \%$ $(\mathrm{p}=0,161)$.

Bảng 6. Mối liên quan MSI với xâm nhập lympho u

\begin{tabular}{|c|c|c|c|c|c|c|}
\hline & \multicolumn{2}{|c|}{ MSS/MSI-L } & \multicolumn{2}{c|}{ MSI-H } & \multicolumn{2}{c|}{ Tống số } \\
\cline { 2 - 7 } & $\mathbf{N}$ & $\mathbf{\%}$ & $\mathbf{N}$ & $\mathbf{\%}$ & $\mathbf{N}$ & $\mathbf{\%}$ \\
\hline Không & 25 & 67,6 & 6 & 37,5 & 31 & 58,5 \\
\hline Có & 12 & 32,4 & 10 & 62,5 & 22 & 41,5 \\
\hline Tống số & $\mathbf{3 7}$ & $\mathbf{6 9 , 8}$ & $\mathbf{1 6}$ & $\mathbf{3 0 , 2}$ & $\mathbf{5 3}$ & $\mathbf{1 0 0 , 0}$ \\
\hline
\end{tabular}

Nhận xét: U MSI-H hay có xâm nhập lympho vào u (62,5\% so với 32,4\%) $(p=0,04)$.

Bảng 7. Mối liên quan MSI với phản ứng lympho dạng Crohn

\begin{tabular}{|c|c|c|c|c|c|c|}
\hline \multirow{2}{*}{} & \multicolumn{2}{|c|}{ MSS/MSI-L } & \multicolumn{2}{c|}{ MSI-H } & \multicolumn{2}{c|}{ Tống Số } \\
\cline { 2 - 7 } & $\mathbf{N}$ & $\mathbf{\%}$ & $\mathbf{N}$ & $\mathbf{\%}$ & $\mathbf{N}$ & $\mathbf{\%}$ \\
\hline Không & 30 & 81,1 & 5 & 31,3 & 35 & 66,0 \\
\hline Có & 7 & 18,9 & 11 & 68,7 & 18 & 34,0 \\
\hline Tống số & $\mathbf{3 7}$ & $\mathbf{6 9 , 8}$ & $\mathbf{1 6}$ & $\mathbf{3 0 , 2}$ & $\mathbf{5 3}$ & $\mathbf{1 0 0 , 0}$ \\
\hline
\end{tabular}

Nhận xét: Nhóm MSI-H có phản ứng lympho dạng Crohn cao nhất là $68,7 \%$ so với thế MSS/MSIL là $18,9 \%(p=0,0004)$.

\section{BÀN LUÂN}

Tình trang MSI và thể lâm sàng: Bênh sinh của ung thư ĐTT vẫn chưa rõ, thường nó được xác định bằng 2 con đường phân tử của sự bất ổn gen. Một là sự bất ổn nhiếm sắc thể, nó liên quan tới các gen ức chế ung thư hoăc gen ung thư nào đó như là $\mathrm{APC}$, KRAS và P53. Hai là sứ bất ổn vi vệ tinh (MSI) nó là do sự khiếm khuyết hệ thống sửa chữa ghép cặp sai và chiếm khoảng 15\% tất cả các ung thư ĐTT. Các bệnh nhân có MSI-H có tiên lượng và đáp ứng với điều trị khác với các bệnh nhân ổn định vi vệ tinh (MSS). Do vậy việc xác định MSI có ý nghĩa rất quan trọng, không chỉ để sàng lọc hội chứng Lynch mà còn giúp phân biệt giữa ung thư $Đ T T$ khiếm khuyết hệ thống sửa chữa bắt cặp sai với ung thư ĐTT MŚS, nó sẽ cung cấp các thông tin có giá trị cho tiên lượng và việc cả thể hóa trong điều trị. Bảng 1 cho thấy tỷ lệ ung thư ĐTT giai đoạn sớm có MSI-H chiếm tỷ lệ 30,2\%, trong khi đó các u có MSS/MSI-L có tỷ lệ là $69,8 \%$. Các nghiên cứu cho thấy rằng các khối u đại trực tràng có $15 \%$ là MSI-H, $12 \%$ MSI-L và $73 \%$ MSSS [9]. Trong một nghiên cứu trước đây của chúng tôi cho thấy MSI-H ở ung thư ĐTT của tất cả các giai đoạn chiếm $25,4 \%$. Như vậy chứng tỏ, MSI găp ở giai đoạn sớm chiếm tỷ lệ cao. Dựa vào kểt quả xét nghiệm sự mất ổn định 4 dấu ấn bằng HMMD, ung thư $Đ T T$ được chia thành 3 thể lâm sàng: đơn lẻ, đơn lẻ/LS và LS [7]. Trong nghiên cứu của chúng tôi (bảng 2), ung thư ĐTT đơn lẻ chiếm phần lớn $(69,8 \%)$, các trường hợp đơn lẻ/LS là $16,7 \%$, trong khi đó hội chứng Lynch là 13,5\%. Nhìn chung, ung thư ĐTT thể Lynch chiếm tỷ lệ thấp, tương tự như nghiên cứu trước đây của chúng tôi. Bệnh nhân có hội chứng Lynch mắc bênh ở giai đoạn thấp hơn so với bệnh nhân với các loại ung thư ĐTT khác, và 
ít biểu hiện di căn. Gryfe et al báo cáo rằng $17 \%$ bệnh nhân ung thư ĐTT có MSI trẻ hơn 50 tuổi; tỷ suất chênh đối với bệnh nhân có khối u liên quan MSI là 0,42 , so với bệnh nhân trong cùng nhóm với khối u không MSI [7].

Giai đoạn TNM sau mổ: Bệnh nhân có hội chứng Lynch mắc bệnh ở giai đoạn thấp hơn so với bệnh nhân với các loại ung thư ĐTT khác và ít biểu hiện di căn. Gryfe et al báo cáo rằng $17 \%$ bệnh nhân ung thư ĐTT có MSI trẻ hơn 50 tuổi; tỳ suất chênh đối với bệnh nhân có khối u liên quan MSI là 0,42 , so với bệnh nhân trong cùng nhóm với khối u không MSI. Bệnh nhân có khối u với MSI có tỷ lệ tử vong thấp hơn, gồm cả các bệnh nhân bị ung thư giai đoạn IV $[5,7]$. Kết quả HMMD MSH2 và MLH1 bất thường dự đoán độc lập kết quả tốt hơn ở những bệnh nhân với khối u ĐTT giai đoạn II-T3. Do đó, phát hiện của MSI ở một bệnh nhân với ung thư ĐTT là một yếu tố tiên lượng tốt, đặc biệt là ở những bệnh nhân trẻ tuổi $[4,5,7,8]$. Bảng 3 cho thấy rằng u MSI-H giai đoạn II có tỷ lệ mắc cao hơn giai đoạn I (68,8\% so với $32,2 \%)$. Trong bảng 4, thể LS gặp tỷ lệ thấp hơn ở giai đoạn I $(14,3 \%)$ và cao hơn ở giai đoạn II là $85,7 \%$.

Typ MBH: Chúng tôi nhận thấy rằng (bảng 5) typ tuyến nhày, tế bào nhẫn, tủy chiếm tỷ cao hơn ở ung thư ĐTT giai đoạn I-II MSI-H là $31,2 \%, 6,3 \%$ và $6,3 \%$ so với các u của những typ này có MSS/MSI-L. Jenkins et al. cho thây $11 \%$ u MSI-H là typ nhày hoặc các typ $\mathrm{MBH}$ không phải tuyến khác (10 trường hợp là tế bào nhẫn và 1 là typ tủy), 21\% u MSI-H là kém biệt hóa [9]. Tác giả nhận thấy rằng tất cả các đặc điểm đặc hiệu cho u MSI-H là typ MBH đặc biệt, có xấp xỉ $90 \%$ UTB tuyến (không chế nhày) hoặc là MSI-L hoặc MSS [9]. Trong nghiên cứu của Alexander et al. thấy rằng typ tủy, tuyến kém biệt hóa đặc biệt hay kết hợp với MSI-H. Typ tế bào nhẫn được phát hiên chỉ ở $13 \% \mathrm{u} \mathrm{MSI}-\mathrm{H}$ $(12 / 92)$ và $5 \%$ u MSS $(12 / 231)(P=0,02 ; O R$ 2.7). UTBM nhày được xác định ở $15 \% \mathrm{u}$ MSI-H $(14 / 92)$ và $5 \%$ u MSS $(12 / 231 ; P=0,005 ; O R$ 3.3). Có sự khác biệt có ý nghĩa về tỷ lệ thành phần nhày giữa u MSI-H và MSS $(P=0.0003$; odd ratio: 3.7).

Sự xâm nhập lympho vào mô u: Sự xâm nhập lympho u được xác định khi các tế bào lympho xâm nhập vào tế bào $u$ khi có ít nhất 5 tế bào lympho ở ít nhất một vi trường có độ phóng đại cao $(\times 40)$ và ít nhất 10 vi trường có độ phóng đại cao [9]. Khối u với MSI có số lượng lớn tế bào lympho xâm nhập khối u được kích hoạt và gây độc tế bào; phản ứng lympho bào có liên quan một cách độc lập với thời gian sống thêm kéo dài hơn. Nghiển cứu báo cáo rằng các khối u ĐTT có xâm nhập lympho bào có liên quan với thời gian sống thêm lâu hơn; trên thực tế, xâm nhập lympho có thể là một yếu tố tiên lượng tốt hơn so với giai đoạn GPB. Kết quả HMMD MSH2 và MLH1 bất thường dự đoán độc lập kết quả tốt hơn ở những bênh nhân với khối u ĐTT giai đoan II-T3. Do đó, phát hiện của MSI ở một bềnh nhần với ung thư ĐTT là một yếu tố tiên lượng tốt, đặc biệt là ở những bệnh nhân trẻ tuổi $[4,7,8]$. Trong nghiên cứu của chúng tôi (bảng 6), nhận thấy các ung thư ĐTT giai đoạn I-II MSI-H hay có xâm nhập lympho vào u (62,5\% so với $32,4 \%$ u thuộc nhóm MSS/MSI-L. Jenkins et al. nhận thây $28 \%$ u MSI-H có phản ứng lympho dang Crohn và $26 \%$ u MSI-H có xâm nhập lympho vào mô u [9]. Tác giả nhận thấy đặc điểm có độ nhạy nhất đối với u MSI-H là xâm nhập lympho vào mô u, có khoảng $3 / 4$ các u MSI-H có đặc điểm này. Alexander et al. thấy rằng sự xâm nhập lympho u ở $21 \%$ các u MSI-H, trong khi đó chỉ 3\% u MSS có xâm nhập lympho u $(P<0.000001)$. Sự xâm nhập lympho u hứa hẹn chiến lược điêu trị trong tương lai bằng cách loại trừ các tế bào u reo rắc hoặc di chuyển trong tuần hoàn. Hệ thống miễn dịch nhận biết u kém, nhưng ở khối u MSI-H với sự xâm nhập lympho $u$ đã cho thấy rằng cơ chế hoạt hóa tế bào $T$ độc.

Phản ứng đệm lympho dạng Crohn: Phản ứng đệm lympho dạng Crohn được ghi nhận khi có ít nhất 4 nốt lympho trong một vi trường có độ phóng đại thấp $(\times 4)$ vượt ra khỏi bờ xa của khối u và thường nằm trong lớp hạ thanh mạc hoặc mô mõ mạc treo [9]. Phản ứng dạng Crohn rõ thường phổ biến, hầu hết các trường hợp gồm các đám lympho nhưng không rõ hoăc khồng có tâm mầm. Trong nghiên cứu của chúng tôi (bảng 7), ung thư ĐTT giai đoạn I-II nhóm MSI-H có phản ứng lympho dạng Crohn cao nhất là $68,7 \%$ so với thể MSS/MSI-L là 18,9\%. Trong nghiên cứu của Alexander et al. thấy rằng 49\% MSI (35/71) có phản ứng lympho dạng Crohn, trái lại với $36 \%$ $(48 / 133)$ u MSS $(P=0,07 ; O R: 1.7)$. Jenkins et al. nhận thây $28 \%$ u MSI-H có phản ứng lympho dạng Crohn [9]. Sự phản ứng lympho dạng Crohn quanh mô u đã được xác định như là một yếu tố tiên lượng độc lập. Một nghiên cứu 344 UTBM tuyến đại tràng phải, đặc điểm này cho thấy có vai trò dự báo thời gian sống 5 năm được cải thiện ở 27\% bệnh nhân (96/344).

\section{KẾT LUÂN}

Qua nghiên cứu tình trạng MSI bằng HMMD 
trên 53 trường hợp ung thư ĐTT giai đoạn I-II, chúng tôi rút ra một số kết luận sau:

MSI-H có tỷ lệ mắc cao hơn u MSS/MSI-L ở giai đoạn I và thẩp hơn ở giai đoạn II. Trong đó, thể LS gặp tỷ lệ cao ở giai đoạn II và thấp nhất ở giai đoạn I.

Ung thư ĐTT giai đoạn I-II có MSI-H chiếm tỷ cao ở các typ nhày, tể bào nhẫn, tủy, hay có xâm nhập lympho vào u và có phản ứng lympho dạng Crohn cao nhất.

TÀI LIỆU THAM KHẢO

1. Cunningham, JM, Kim CY, Christensen ER, Tester DJ, Parc Y, Burgart LJ, Halling KC, McDonnell SK, Schaid DJ, Walsh Vockley C, Kubly $\mathbf{V}$, Nelson $H$, Michels VV, Thibodeau SN" (2001), "The frequency of hereditary defective mismatch repair in a prospective series of unselected colorectal carcinoma", Am J Hum Genet, 69: 780-790. .

2. De, la Chapelle A (2004), "Genetic predisposition to colorectal cancer", Nat Rev Cancer, 769-780.

3. Greenson, JK, Bonner JD, Ben-Yzhak $\mathbf{O}$, Cohen HI, Miselevich I, Resnick MB, Trougouboff $P$, Tomsho LD, Kim E, Low M, Almog R, Rennert G, Gruber SB. Phenotype of microsatellite unstable colorectal carcinomas: Well- differentiated and focally mucinous tumors and the absence of dirty necrosis correlate with microsatellite instability. Am J Surg Pathol 2003; 27: 563- 570.

4. Hall, G, Clarkson A, Shi A, Langford E, Leung H, Eckstein RP, Gill AJ. Immunohistochemistry for PMS2 and MSH6 alone can replace a four antibody panel for mismatch repair defciency screening in colorectal adenocarcinoma. Pathology 2010; 42: 409-413.

5. Kurzawski, G, J. Suchy, T. De .bniak (2004). Importance of microsatellite instability (MSI) in colorectal cancer: MSI as a diagnostic tool. Annals of Oncology 15 (Supplement 4): iv283 - iv284.

6. Amin, MB et al. AJCC Cancer Staging Manual eighth edition. Springer, 2017, 251-395.

7. Boland, CR, Goel A. Microsatellite instability in colorectal cancer. Gastroenterology 2010; 138: 2073-2087.

8. Umar, A, Boland CR, Terdiman JP et al (2004). Revised Bethesda Guidelines for hereditary nonpolyposis colorectal cancer (Lynch syn- drome) and microsatellite instability. J Natl Cancer Inst 2004; 96: 261-268.

9. Jenkins, MA, Hayashi S, O'shea AM et al. Pathology Features in Bethesda Guidelines Predict Colorectal Cancer Microsatellite Instability: A Population-Based Study. Gastroenterology. 2007 July ; 133(1): 48-56.

\section{GIÁ TRI CỦA CYSTATIN C TRONG CHẨN ĐOÁN SỚM TỔN THƯO'NG THÂ̂N Ở BỆNH NHÂN ĐÁI THÁO ĐƯỜNG TYP 2 TẠI BÊ̂NH VIÊ̂N TRUNG ƯƠNG THÁI NGUYÊN}

\section{TÓM TẮT}

Bệnh thận do đái tháo đường (ĐTĐ) là biến chứng mạch máu nhỏ xuất hiện sớm, gặp với tî lệ cao, là nguyên nhân gây suy thận giai đoạn cuối cần phải lọc máu định kì, việc phát hiện sớm sự suy giảm độ lọc câu thận đối với bệnh nhân ĐTĐ là hết sức cân thiểt. Mục tiêu: Xác định giá trị của cystatin $C$ huyết tương trong phát hiện sớm tổn thương thận ở bệnh nhân đái tháo đường týp 2. Đối tượng và phương pháp nghiên cứu: Mô tả cắt ngang trên 89 bệnh nhân ĐTĐ týp 2 điều trị ngoại trú tại Khoa khám bệnh Bệnh viện trung ương Thái Nguyên. Kết quả: Có mối tưởng quan thuận mức độ chặt chẽ giữa nồng độ cystatin C với creatinin huyết tương, giữa $\mathrm{MLCT}_{\text {cys }}$ với $\mathrm{MLCT}_{\text {cre }}$ ở BN đái tháo đường týp 2; Có mối tương quan nghịch mức độ chặt chẽ giữa nồng độ cystatin $C$ với

*Trường Đại học Y Dược Thái Nguyên

**Bênh viển Trung ướng Thái Nguyên

Chịu trách nhiệm chính: Bùi Thị Thu Hương

Email: huongbuithithu@tnmc.edu.vn

Ngày nhận bài: 12.11.2020

Ngày phản biện khoa họ: 24.12.2020

Ngày duyệt bài: 4.01.2021

\section{Bùi Thị Thu Hương*, Nguyễn Thu Giang**}

$\mathrm{MLCT}_{\text {cre }}$ ở BN đái tháo đường týp 2; Ước lượng MLCT bằng cystatin $\mathrm{C}$ làm tăng thêm $25 \%(13 / 89)$ bệnh nhân suy thân $(M L C T<60 \mathrm{ml} / \mathrm{p})$. Phân tích đường cong ROC với giá trị tới hạn GFR $60 \mathrm{ml} /$ phút. Diện tích dưới đường cong (AUC) của cystatin C là 0,812 lớn hơn AUC của creatinin là 0,711 . Sự khác biệt có ý nghĩa thống kê $(p<0,05)$. Kết luận: Cystatin $C$ huyết tương có thể phản ánh được sự giảm mức lọc câu thận sớm ở bệnh nhân Đái tháo đường týp 2.

Ti̛ khóa: CystatinC, bệnh thận do đái tháo đường, mức lọc cầu thận ước tính (eǴFR)

\section{SUMMARY \\ VALUES OF CYSTATIN C IN EARLY \\ DIAGNOSIS OF RENAL DISEASE IN \\ PATIENTS WITH TYP 2 DIABETES IN \\ THAINGUYEN NATIONAL HOSPITAL}

Diabetic kidney disease (diabetes mellitus) is a small vascular complication that occurs early, with a high rate, is the cause of end-stage renal failure requiring periodic dialysis, early detection of the decrease in filtration Glomerular glomeruli for diabetic patients is extremely necessary. Objective: Determine the value of plasma cystatin $C$ in early 